\title{
The Hyperimmunoglobulinemia E Syndromes: A Literature Review
}

\author{
Slavica Hristomanova*, Mirko Spiroski \\ Institute of Immunobiology and Human Genetics, Faculty of Medicine, Ss Cyril and Methodius University of Skopje, Republic \\ of Macedonia
}

\begin{abstract}
Citation: Hristomanova S, Spiroski M. The Hyperimmunoglobulinemia E Syndromes: A Literature Review. OA Maced J Med Sci. 2013 Literature Review. OA Maced J Med Sci. 2013
Dec 15; 1(1):117-126. Dec 15; 1(1):117-126.
http://dx.doi.org/10.3889/oamjms.2013.024 Key words: hyper-immunoglobulin $E$ syndromes (HIES); dominant form (AD-HIES); recessive form (AR-HIES); STAT3; review article.

'Correspondence: Slavica Hristomanova, MD, $\mathrm{PhD}$ candidate. Institute of Immunobiology and Human Genetics, Faculty of Medicine, Ss Cyril and Methodius University of Skopje, 50. Divizija No 16, PO Box 60, 1109 Skopje, Republic of Macedonia.E-mail: cacka_h@yahoo.com

Received: 06-Apr-2013; Revised: 10-Sep2013; Accepted: 11-Sep-2013; Online first: 20-Sep-2013

Copyright: $\odot 2013$ Hristomanova S. This is an open-access article distributed under the terms of the Creative Commons Attribution License, which permits unrestricted use, distribution, and reproduction in any medium, provided the original author and source are credited.

Competing Interests: The authors have declared that no competing interests exist.
\end{abstract}

\begin{abstract}
The hyper-immunoglobulin E (IgE) syndromes (HIES) are primary immunodeficiencies characterized by the recurrent staphylococcal abscesses, recurrent pneumonia and highly elevated serum IgE levels. There are two forms of HIES: a dominant form (AD-HIES) and a recessive form (AR-HIES). AD form of HIES is caused by mutations in STAT3 and the AR form is caused by mutations in DOCK8 and TYK2. These syndromes have different clinical presentations and outcomes. AD-HIES is a multisystem disorder that includes abnormalities of the skin, lungs, musculo-skeletal system and dental system. In contrast, these symptoms in patients with AR-HIES are missing. AR-HIES patients have severe viral infections and may develop neurological complications. This review article discusses the clinical presentation and laboratory findings in both forms of HIES, as well as the establishment of diagnose, inheritance, molecular genetics and immunological abnormalities of HIES.
\end{abstract}

\section{Introduction}

The hyper-immunoglobulin $\mathrm{E}$ syndromes (HIES) 147060 and 243700 (Mendelian Inheritance in Man, a catalogue of inherited diseases) refer to two related immunodeficiency disorders that can manifest in a variety of ways [1]. Initially, HIES was described in 1966 by Davis and Wedgwood, who associated staphylococcal skin infections in newborns with what they termed the "Job's syndrome", along with skin lesions lacking typical signs of inflammation (cold abscesses) [2, 3].

Buckley and colleagues (1972) then further characterized the condition by associating severe dermatitis, joint hyperextensibility, asymmetric facies and especially the highly elevated serum IgE levels with it, which lead them to phrase the term "Hyper lgE syndrome" [4].

In the following years, an ever-increasing effort was devoted to identify describe different HIES cases [5-8], which revealed additional characteristic clinical symptoms and motivated further research into the causative mechanisms thereof [9-17], while others suggested a genetic inheritance pattern [18].

In 2004, Renner et al. distinguished between the autosomal recessive (AR) and autosomal dominant (AD) HIES forms, based on their clinical appearance [19].

Minegishi and colleagues [20] described the potential cause for the AR-HIES form, a homozygous deletion within the TYK2 gene, in 2006. In continued investigations, Minegishi and colleagues identified the mechanism underlying AD-HIES by revealing heterozygous STAT3 mutations in patients with ADHIES [21]. In 2007, Holland et al. found missense mutations and in-frame single-codon deletions within STAT3 in AD-HIES patients and their families, thereby further underscoring the importance of STAT3. They concluded that STAT3 mutations are present in sporadic and dominant forms of the hyper-lgE syndrome [22]. 
While several studies had identified mutations responsible for the AD form of HIES, apart from one possible exception, no mutations had been linked to the AR-HIES form until 2009. Then, in 2009, Zhang et al. reported on a group of AR-HIES patients exhibiting homozygosity or compound heterozygosity for DOCK8 gene deletions or mutations [23]. Alsum et al. identified novel DOCK8 mutations in continued investigations of AR-HIES patients [24].

The consensus involves the acknowledgment of two HIES forms: a dominant and a recessive form caused by mutations in either STAT3 or DOCK8 and TYK2, respectively. These two different syndromes have distinct presentations and outcomes with only elevated IgE serum levels in common.

In this review we will address the differences between the two HIES forms in terms of clinical features, laboratory abnormalities, diagnosis, inheritance, molecular genetics and immunological abnormalities.

\section{Clinical characteristics of HIES}

HIES is a multisystem disorder affecting the skin, lungs, musculoskeletal system, the face, central nervous system, dentition and the vascular system. All of the clinical findings in HIES vary with age and among individuals, with further differences arising due to the different mutations characteristic of either the autosomal dominant HIES (AD-HIES) or the autosomal recessive HIES (AR-HIES) form.

\section{AD-HIES (STAT3 mutations)}

Skin. A newborn rash is usually the first manifestation of AD-HIES. The rash is pustular and eczematoid and usually begins within the first month of life. It typically affects the scalp and the face first $[25,26]$. In a group of 43 patients, $19 \%$ (8 babies) were born with the rash, while in $53 \%$ (23 babies) the rash appeared within the first week of life [27]. The biopsies reveal eosinophilic infiltrates and bacterial cultures. Staphylococcus aureus is the most common bacteria. The rash often persists throughout childhood, but it can be well controlled with appropriate therapy. Furuncles are characteristic for the diagnosis and are classical findings typical of the disease. The severity of inflammatory symptoms is often quite variable. The "cold" abscesses are also common and even with the absence of the external inflammation signs there is apparent pus and again Staphylococcus aureus is the most common bacteria.

Lung. Recurrent pyogenic pneumonias are typical. They usually start in early childhood. The most common pathogens are S. aureus, with Streptococcus pneumoniae and Haemophilus influenzae also occurring frequently $[8,28]$. Similarly to the "cold" abscesses, individuals often lack systemic signs of inflammations. Healing of the pneumonia is often complicated with pneumatoceles and bronchiectasis. The structural abnormalities persist and are quite significant because later they are sites of fungal (typically Aspergillus) and Gram-negative (typically Pseudomonas) infections. These infections are the major cause of morbidity and mortality [29]. Mold infections can invade blood vessels leading to lifethreatening hemoptysis and may disseminate to extrapulmonary sites of infection. There are also opportunistic infections in HIES patients. Pneumocystis jiroveci pneumonia was described as the initial pneumonia in HIES infants [30].

Other infections. Mucocutaneous candidiasis is characteristic for patients with STAT3 mutations and is typically presented as oral thrush, vaginal candidiasis or onychomycosis [8]. Candida infections are very rare and in the most cases are nosocomial in origin. The uncommon yeast infections are often localized as disseminated histoplasmosis of the tongue and Cryptococcus infection in the intestinum [31, 32].

Musculoskeletal abnormalities and facial appearance. Skeletal and facial abnormalities are typical only of the AD form of HIES. Some of the musculoskeletal abnormalities in HIES patients were described and recognized in the original reports by Davis et al. in 1966 and Buckley et al. in 1972 [2, 4]. Musculoskeletal abnormalities are typical for AD-HIES patients and include scoliosis, minimal trauma fractures, osteopenia, hyperextensibility and degenerative joint disease [8]. Scoliosis occurs in 75\% of the patients and may develop during adolescence. The developing pattern is similar to idiopathic scoliosis. It can also develop as a secondary complication because of length discrepancy, lung disease with volume loss, or lung resections. The degree of scoliosis can vary and may be so severe as to require surgical treatment. Degenerative joint disease, especially of the spine, often manifests in the third and fourth decade of life and may require surgical repair. Minimal trauma fractures mainly occur on the ribs, long bones and pelvic bones. They can occur independently of osteopenia. It has been suggested that osteopenia, which is common in HIES patients, may be cytokine or immune driven, and the fractures that occur are not in the same sites which are typical of osteoporosis in menopausal females. Bone resorption in patients with HIES is unusually high and has been attributed to concomitant abnormalities in the prostaglandin synthetic pathway $[33,34]$.

The facial appearance that is typical only for the patients with STAT3 mutations develops during childhood and adolescence and it was also noted in the very first reports of the disease. The patients were described as with unusual faces, with coarse features $[2,4]$. The face of a HIES patient is unequal, 
asymmetric and the main typical features are broad nose, deep-set eyes and a prominent forehead [7, 8, 28].

Dental abnormalities. Dental anomalies are consistent features of STAT3 patients [8]. They retain some of their primary teeth after the normal primary dental exfoliation age. It has been suggested that reduced resorption of primary tooth roots leads to their prolonged retention, which in turn prevents the appropriate eruption of the permanent teeth [35].

Nervous system. There is craniosynostosis of different degrees. Smithwick et al. in 1978 reported three HIES cases associated with cranial abnormalities and suggested that the abnormalities can provide better understanding of the molecular mechanisms underlying the impaired regulation of immunoglobulin $E$ [36]. The fourth case was reported in 1985, where a 9-year-old boy with premature fusion of the sagittal and lambdoid suture suffered from scaphocephaly [37]. Other recurrent malformations include the Chiari 1 malformations. In a study of 50 HIES patients, Chiari type 1 malformations were found in nine, while five patients had lacunar infarctions and two patients had infectious complications that were shown to be of fungal origin [38].

The eye. Abnormalities of the eye as part of the nervous system were also reported. Lee et al. in 2003 described a 57 year old woman diagnosed with HIES at the age of 22 years, with extensive xanthelasma [39]. Additionally, ophthalmologic pathologies such as giant chalazia were reported [40].

Vascular abnormalities. The first report of coronary artery aneurysms in AD-HIES was in 2007, with the description of two patients (age 43 and 48). They both had coronary artery aneurysms identified on cardiac catheterization [41].

Malignancies. Lymphomas are most frequent in HIES patients. The increased risk of malignancies is associated with the AD form of HIES. A case report in 1989 described a 7-year-old boy with retroperitoneal Burkitt's lymphoma with probable metastasis to the brain [42]. After 15 years Leonard et al. reported of the case of a 22-year-old male HIES patient with a diffuse large B-cell lymphoma involving second lumbar vertebrae and spleen. They have reviewed reported cases of lymphomas and showed that there is an increase in relative risk of 259 (95\% confidence interval 102, 416) [43]. During the same year, an additional report documented pulmonary adenocarcinoma in a HIES patient [44].

\section{AR-HIES (DOCK8 mutations)}

Skin. Renner ED et al. studied a large group of 13 AR-HIES patients originating from 6 consanguineous families and 68 of their relatives. They concluded that the primary clinical manifestations of this form are severe eczema and recurrent skin infections [19]. Clinical manifestations of the skin started early in life, but not necessarily during the newborn period. The skin manifestations in AR-HIES differs from AD-HIES in the much higher incidence of cutaneous viral infections including Molluscum contagiosum, herpes simplex and varicella zoster virus infections.

Table 1: Summary of symptoms characteristic of STAT3 ADHIES and DOCK8 AR-HIES.

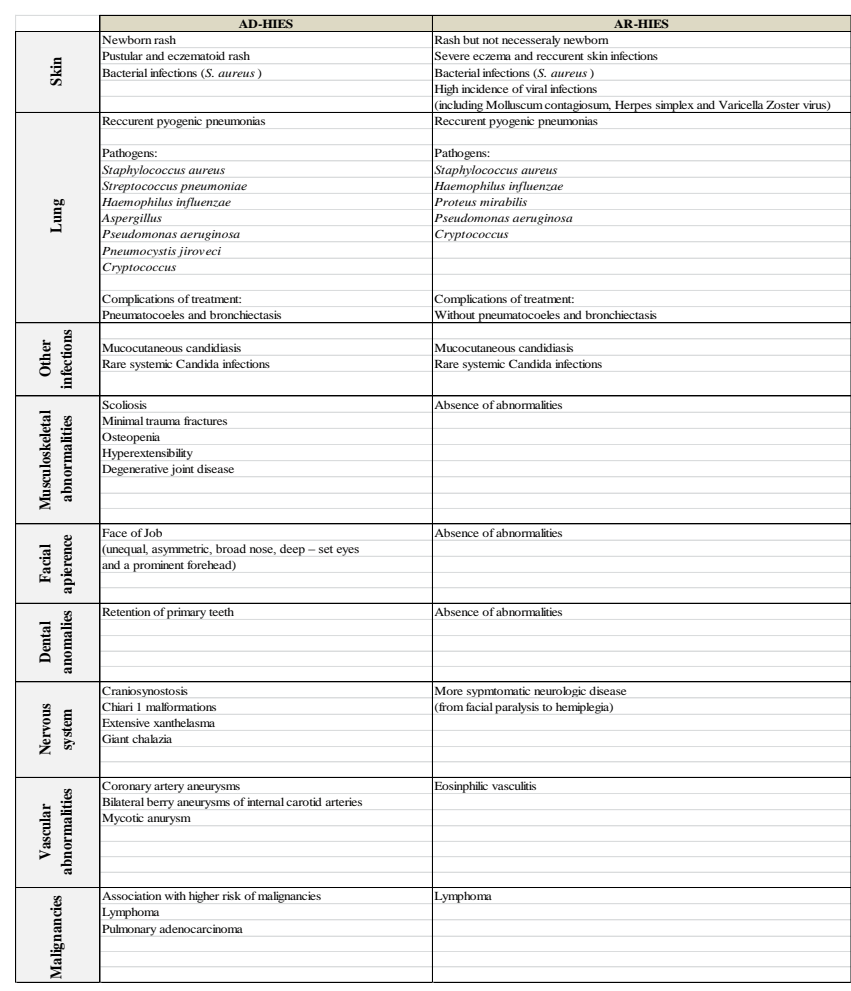

Lung. Patients with AR-HIES also have sinopulmonary infections and the most common pathogens are $S$. aureus, Haemophilus influenzae, Proteus mirabilis, Pseudomonas aeroginosa and Cryptococcus. The most significant difference in the clinical features of the different mutations causing the two HIES forms is that AR-HIES patients heal their lung infections without forming pneumatoceles and bronchiectasis [19].

Other infections. Mucocutaneous candidiasis is also characteristic of patients with DOCK8 and TYK2 mutations, as well as oral thrush, vaginal candidiasis or onychomycosis [8, 19]. Candida infections are very rare and in most cases are of nosocomial origin. The uncommon yeast infections are often localized, as the already mentioned disseminated histoplasmosis of the tongue and Cryptococcus infection in the intestinum [31, 32].

Musculoskeletal abnormalities and facial appearance. Patients with this form of HIES lack the connective tissue and skeletal abnormalities [19].

Dental abnormalities. AR-HIES patients have normal primary tooth exfoliation [19].

Nervous system. The patients with AR-HIES have more symptomatic neurologic disease. In a 
study of 13 affected patients and 68 of their relatives, Renner et al. in 2004 found neurologic symptoms in seven patients. The symptoms were ranging from facial paralysis to hemiplegia [19].

Vascular abnormalities. Freeman et al, reported bilateral berry aneurysms of internal carotid arteries and mycotic aneurysm as causes of death in a HIES patient [29]. It is suggested that the neurological complications in AR-HIES may be manifestations of possible vasculitis.

\section{AR-HIES (TYK2 mutations)}

There are only two known TYK2 HIES cases described in the literature $[20,45]$. One of the patients had a history of infantile atopic dermatitis with recurrent infections, such as otitis media, sinusitis, pneumonias, and skin abscesses, starting from 12 months of age. Ten months later he developed BCG lymphadenitis. He experienced Staphylococcus aureus bacterial infections, as well as viral and fungal infections, such as molluscum contagiosum, herpes simplex infection of skin and mucosa, and oral candidiasis. The patient developed severe non-Typhi Salmonella gastroenteritis leading to sepsis. The patient did not have any skeletal abnormalities. This TYK2 deficient patient was phenotypically distinct from the other autosomal recessive HIES patients with DOCK8 mutations, having non-Typhi Salmonella infections and BCG lymphadenitis, because of which Minegishi et al. proposed that this case represents a subset of the AR-HIES form [20].

The second patient did not have atopy, asthma, skin candidiasis, boils, folliculitis, or cold abscesses. However, the patient developed two disseminated infections with intracellular organisms, the first one of which occurred 6 months after BCG vaccination at an age of 8 months, when axillary lymphadenopathy was diagnosed, while the second was a Brucella spp. infection that took place 7 years later. After the infection, the patient had an episode with left temporal, occipital, and bilateral parietal brain infarcts accompanied by sensorineural hearing loss and residual cognitive impairment. Later, the patient had severe herpes zoster infection [45].

\section{Laboratory Findings}

\section{AD-HIES (STAT3 mutations)}

The main laboratory finding of HIES is the abnormally high $\operatorname{lgE}$ level in the serum that may exceed $2000 \mathrm{U} / \mathrm{ml}$, even reaching $100000 \mathrm{U} / \mathrm{ml}$ [8, $46,47]$. For the diagnostic perspective, increased $\lg E$ levels are very helpful in establishing HIES, for which the $2000 \mathrm{U} / \mathrm{ml} \mathrm{lgE}$ concentration may be used as a cut-off point [48], including cases where patients suffer from multiple conditions [49].
However, elevated IgE levels alone are not a sufficient, as they are not always present in patients, especially in infants, or are even normal [8]. This is exemplified by a HIES case report of two girls in India (6- and 12-year-old) where the general conclusion was that mildly elevated $\lg E$ levels do not exclude the HIES, especially when other typical symptoms of it are present [50].

Another AD-HIES hallmark is blood eosinophilia, where the eosinophil count does not correlate with $\operatorname{lgE}$ levels. The eosinophil count in peripheral blood exceeds 700 cells/microliter or a rise that is at least $2 \mathrm{SD}$ above the normal range $[47,51]$.

In the majority of cases with AD-HIES the levels of the other immunoglobulin classes are normal $[47,52]$.

In 1979 Schopfer et al. reported the presence of Staphylococcal IgE antibodies and later in 1983 they described a case of Staphylococcus aureus HIES with systemic lupus erythematosus as a late complication. The main goal was to examine the antinuclear autoantibodies and they reported the presence of specific antistaphylococcal and anticandidal $\lg E$ antibodies [53, 54]. On the other hand, several years later there were reports of $A D$ HIES patients, where the existence of elevated, specific IgE antibodies towards Staphylococcus and Candida was interpreted as the first sign of infection typical for HIES patients [55]. However, these findings can also be present in patients with atopic dermatitis, which further underscores the necessity to involve multiple factors when diagnosing HIES [56].

\section{AR-HIES (DOCK8 mutations)}

In AR-HIES, elevated IgE serum levels, as well as eosinophilia are more pronounced than in the $A D$ form of HIES (43), while IgM levels in patients with a DOCK8 deficiency are low [57].

Lymphopenia affected CD4 and CD8 cells in the DOCK8 AR-HIES patients, where the CD8 T cells failed to activate, divide and expand [57].

\section{AR-HIES (TYK2 mutations)}

Laboratory findings revealed mild eosinophilia $(700-800 / \mathrm{mm} 3)$ and high serum $\mathrm{lgE}(2100 \mathrm{IU} / \mathrm{ml})$ with normal amounts of other Ig classes and subclasses in the first described patient with TYK2 defects. All other laboratory data examined were within the normal range, including complement components, oxidative burst of granulocytes, number and size of platelets, lymphocyte subpopulations, and their proliferative responses to mitogens [20].

Laboratory assessment of the second patient 
Table 2: Scoring system with Clinical and Laboratory Tests for Individuals in Kindreds with HIES.

\begin{tabular}{|c|c|c|c|c|c|c|c|c|c|c|}
\hline \multirow[b]{2}{*}{ CLINICAL FINDINGS } & \multicolumn{10}{|c|}{ POINTS $^{a}$} \\
\hline & 0 & 1 & 2 & 3 & 4 & 5 & 6 & 7 & 8 & 10 \\
\hline Highest serum-lgE level $(\mathrm{IU} / \mathrm{ml})^{D}$ & $<200$ & $200-500$ & & & $501-1,000$ & & & & $\begin{array}{l}1,001- \\
2,000\end{array}$ & $>2,000$ \\
\hline Skin abscesses & None & & $1-2$ & & 3-4 & & & & $>4$ & \\
\hline Pneumonia (episodes over lifetime) & None & & 1 & & 2 & & 3 & & $>3$ & \\
\hline Parenchymal lung abnormalities & Absent & & & & & & $\begin{array}{l}\text { Bronchiect } \\
\text { asis }\end{array}$ & & $\begin{array}{l}\text { Pneumato } \\
\text { cele }\end{array}$ & \\
\hline Retained primary teeth & None & 1 & 2 & & 3 & & & & $>3$ & \\
\hline Scoliosis, maximum curvature & $<10^{\circ}$ & & $10-14^{\circ}$ & & $15^{\circ}-20^{\circ}$ & & & & $>20^{\circ}$ & \\
\hline Fractures with minor trauma & None & & & & $1-2$ & & & & $>2$ & \\
\hline Highest eosinophil count $(\text { cells } / \mu l)^{c}$ & $<700$ & & & $700-800$ & & & $>800$ & & & \\
\hline Characteristic face & Absent & & $\begin{array}{l}\text { Mildly } \\
\text { present }\end{array}$ & & & Present & & & & \\
\hline Midline anomaly ${ }^{\mathrm{d}}$ & Absent & & & & & Present & & & & \\
\hline Newborn rush & Absent & & & & Present & & & & & \\
\hline Eczema (worst stage) & Absent & Mild & Moderate & & Severe & & & & & \\
\hline Upper respiratory infections per year & $1-2$ & 3 & $4-6$ & & $>6$ & & & & & \\
\hline Candidiasis & None & Oral & $\begin{array}{c}\text { Fingernail } \\
\mathrm{s}\end{array}$ & & Systemic & & & & & \\
\hline Other serious infections & None & & & & Severe & & & & & \\
\hline Fatal infection & Absent & & & & Present & & & & & \\
\hline Hyperextensibility & Absent & & & & Present & & & & & \\
\hline Lymphoma & Absent & & & & Present & & & & & \\
\hline Increased nasal width ${ }^{\mathrm{e}}$ & $<1 \mathrm{SD}$ & $1-2 \mathrm{SD}$ & & $>2 \mathrm{SD}$ & & & & & & \\
\hline High palate & Absent & & Present & & & & & & & \\
\hline Young - age correction & $>5$ years & & & $2-5$ years & 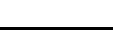 & $1-2$ years & & $\leq 1$ year & & \\
\hline
\end{tabular}

with TYK2 defects during chronic infection demonstrated normal nitroblue tetrazolium test, normal serum $\lg G$, $\lg M$, $\lg A$, and mildly elevated $\lg \mathrm{E}$ [45].

\section{Diagnosis}

In 1999, the National Institutes of Health (NIH) developed a scoring system for AD- HIES diagnosis in patients and their families [27]. The scoring system is based on clinical and laboratory test criteria (Table 2).

The assigned points are based on the incidence and specificity of the various AD-HIES diagnostic markers. The more specific AD-HIES features in Table 2 have bigger importance than findings of lower specificity or are common in the general population.

Table 2 illustrates the estimation of common findings in AD-HIES patients which we have previously described here. However, some of them cannot be confirmed in young children due to later onset (scoliosis, face of Job, retained primary teeth). Furthermore, the number of infection episodes and fractures in AD-HIES patients increases with their age. That is why this scoring system includes a correction for the age, thereby avoiding false-negative scores in children. Studies that are more recent require a score of 40 as an inclusion criterion, since the NIH scoring system is prone to high variability [58].

Table 3: Scoring system that can be applied towards categorizing potential HIES patients.

\begin{tabular}{ll}
\hline Points & Presence of HIES \\
\hline$\geq 15$ & Likely present \\
$10-14$ & Indeterminate \\
$<10$ & Unlikely present \\
\hline
\end{tabular}

The patients in this study were divided based on this scoring system in several groups (Table 3 ).

\section{Inheritance}

Initial studies of subsequent generations exhibiting infections, rash and eosinophilia done by Blum [59] and later the studies by Buckley and Backer [10] lead to the proposal of an autosomal dominant, gender-independent inheritance pattern of HIES. This was later confirmed in a larger study by Grimbacher et al. further establishing that HIES is inherited in an autosomal dominant manner with variable expressivity [8].

However, previously Leung et al. suggested that the $A D$ form of HIES may also be of sporadic origin, completely lacking family history or consanguinity [60]. In 2004, Renner et al. described an autosomal-recessive form of HIES, thereby establishing - a different, previously unrecognized disease entity that may be genotypically unrelated to AD-HIES [19].

Even though most of the cases are of sporadic origin, we can recognize the $A D$ and $A R$ forms of HIES [47], which in turn may be also referred to as type 1 and type 2 HIES [61].

\section{Molecular Genetics}

\section{AD-HIES (STAT3 mutations)}

In 1999, Grimacher et al. [27] evaluated 19 families affected by heterogenous AD- HIES variants. Aside from the scoring of the clinical and laboratory findings, they genotyped the family members with 
polymorphic markers specific for a possible candidate region on chromosome 4. They selected this chromosome region because of a previous case report of a 17-year old male with AD-HIES, autism and mild mental retardation. In this report, Grimbacher et al. discovered an extra, abnormal chromosome in the male's peripheral blood lymphocytes and skin fibroblasts. Further investigations of the chromosome revealed that it was derived from a small, interstitial deletion of a homologue of chromosome 4q21. Therefore, they suggested that the proximal chromosome $4 \mathrm{q}$ can be a candidate region containing diseased genes affecting both HIES and autism [62].

Grimbacher et al. conducted a statistical test (LOD score) based on data from members of the 19 families to establish whether the various loci under investigation are linked to each other. Positive LOD scores favor the presence of linkage, whereas negative LOD scores indicate that linkage is less likely [63]. They found a maximum LOD score of 3.61 with marker D4S428, with recombination factor $\theta=0.0$. Further tests confirmed that the proximal $4 \mathrm{q}$ region contains a disease locus for the syndrome and the fact that six probands did not show linkage to $4 \mathrm{q}$, indicated genetic heterogeneity.

Minegishi and colleagues identified the molecular mechanism underlying AD-HIES in 2007 when they identified heterozygous STAT3 mutations in eight out of fifteen unrelated non-familial HIES patients. They showed that these dominant-negative STAT3 mutations resulted in the AD form of HIES [21]. The analysis of the patients' parents and siblings, however, did not reveal mutant STAT3 alleles and lead Minegishi et al. to propose that these are de novo mutations. They identified five different mutations in the STAT3 DNA-binding domain. In the patients' peripheral blood cells they found impaired responses to cytokines, including IL-6 and IL-10, which indicated the involvement of multiple cytokine pathways in the pathogenesis of AD-HIES.

A month later in 2007, Holland et al. reported on a longitudinal study based on clinical data obtained from AD-HIES patients and their families [22]. They measured cytokine levels exuded by stimulated leukocytes and also quantified gene expression in resting and stimulated cells. The data revealed an IL-6 signaling pathway defect related to downstream signaling mediators and one of which is STAT3. Further sequencing of STAT3 from their patients revealed missense mutations and single-codon inframe deletions. They identified eighteen discrete mutations, five of which were hotspots, that modulate DNA binding and SRC homology 2 (SH2) domains. The mutations that were found in this study are presented in Figure 1 [22]. Holland et al. also concluded that STAT3 mutations are present in the sporadic and dominant forms of the hyper-lgE syndrome.

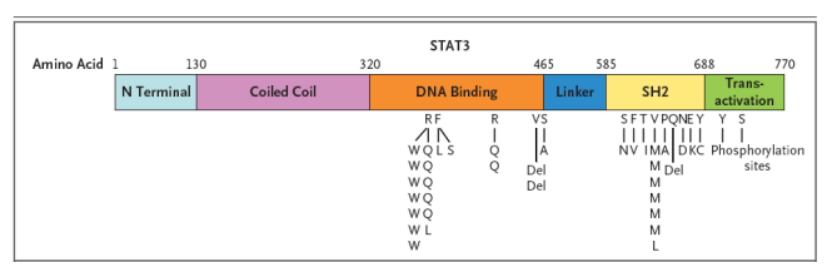

Figure 1: STAT3 Mutations. Wild-type amino acids at the loci where mutations were found are listed immediately below the STAT3 domains, with all the mutant amino acids identified in our study listed below that. The five hot-spot sites, those with multiple mutations, were found in both the DNA-binding and SRC homology 2 (SH2) domains. The amino acid mutations shown (and the underlying nucleotide mutations) in the DNA-binding domain are as follows: $R 382 W \quad(1144 C \rightarrow T), \quad R 382 Q \quad(1145 G \rightarrow A), \quad R 382 L$ $(1145 G \rightarrow T), \quad F 384 L \quad(1150 T \rightarrow C), \quad F 384 S \quad(1151 T \rightarrow C), \quad R 423 Q$ $(1268 G \rightarrow A)$, V463del (1387delGTG), and S465A (1393T $\rightarrow$ G). The amino acid mutations shown (and the underlying nucleotide mutations) in the SH2 domain are as follows: S611N $(1832 \mathrm{G} \rightarrow A)$, F621V $(1861 T \rightarrow G)$, T622I $(1865 C \rightarrow T)$, V637M $(1909 G \rightarrow A)$, V637L $(1909 G \rightarrow T)$, P639A $(1915 C \rightarrow G)$, Q644del (1930delCAG), N647D $(1939 A \rightarrow G), E 652 K(1954 G \rightarrow A)$, and $Y 657 C(1970 A \rightarrow G)$.

The identification of the STAT3 mutations in the AD form of HIES has enabled us to see more deeply into the pathogenesis of this disease, as well as to correlate the clinical manifestation to the accompanying laboratory findings.

\section{AR-HIES (DOCK8 mutations)}

With much effort being invested into the discovery of the genetic basis of HIES, only the ADspecific mutations were determined by 2009 . Then, Zhang et al. reported of gene mutations in 11 patients with AR-HIES, in whom they were unable to detect the DOCK8 protein [23]. More recently, novel DOCK8 mutations and two large deletions were described in a 2013 study by Alsum et al., which was based on a much larger group of patients [24].

\section{AR-HIES (TYK2 mutations)}

In 2006, Minegishi et al. described an ARHIES patient, in whom they identified a homozygous deletion of the GCTT sequence at nucleotide 550 in the TYK2 gene. The deletion resulted in a frameshift and premature truncation of the protein so that they could not detect the TYK2 protein in the patient's T cells. The patient's parents were heterozygous for the TYK2 mutation and they were healthy [20].

This was a reason for Woellner et al. (2007) to analyze TYK2 in 15 additional families with ARHIES. However, they failed to identify mutations and concluded that the TYK2 deficiency is genetically distinct from AR-HIES [64]. In a response, Minegishi et al. (2007) noted that analysis of exon coding regions and the adjacent intronic sequences is not sufficient to identify all genetic alterations, so they suggested that further analysis is needed to exclude a TYK2 deficiency as the cause of AR-HIES in these 
patients [20].

The second diagnosed TYK2 AR-HIES case was a patient of Turkish descent. He had an early termination codon in TYK2 at amino acid position 767 caused by a nine base-pair DNA deletion in exon 16 . As a result, there was no detectable full-length TYK2 protein [45].

\section{Immunological Abnormalities}

\section{AD-HIES (STAT3 mutations)}

There are different immune system disorders in HIES patients, including defective neutrophil chemotaxis, defective production of IFN-y by $\mathrm{T}$ cells, defects in the Th1-dependent cytokine response, distortion of Th1/Th2 cell ratio, decreased memory $T$ cell population, reduced delayed-type hypersensitivity responses [28]. But all of these different disorders failed to explain the susceptibility to specific infections that are seen in AD-HIES, some of which were reported by Milner et al. in 2008. They showed that patients with the AD form of HIES had low IL-17 production by T-cells. They studied three subject groups: healthy controls with no evidence of immunological defects, HIES patients with mutations in STAT3 and individuals (which they named 'HIES like') with some combination of increased IgE levels, atopic dermatitis, skeletal abnormalities and susceptibility to infection, but without STAT3 mutations. They noted that individuals with AD-HIES lacked IL-17 production, but not IL-2, tumour-necrosis factor or interferon- $y$, in response to mitogenic stimulation with staphylococcal enterotoxin B or to antigenic stimulation with Candida albicans or streptokinase. They showed that purified, naive T cells were unable to differentiate into IL-17-producing (TH17) T helper cells in vitro [65]. IL-17 plays an essential role in antimicrobial protection, because IL17 increases the number of neutrophils and expands antimicrobial peptides. Th17 cells produce proinflammatory cytokines involved in innate immunity (TNFa, IL-22, IL-26, IL-6). With this fundamental role of Th17 cells, including cells against Candida antigens, we can explain the pattern of susceptibility to particular infections seen in HIES patients of the AD form $[66,67]$. Recent studies supported the critical role of Th17 cells in the host defense against mucosal Candida infection [68].
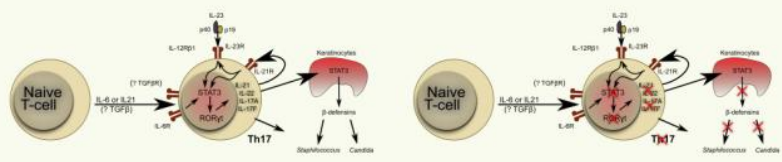

Figure 2: Role of STAT3 (Differentiation of Th17 cells in normal defence - left and in STAT3 deficiency-right).

Since STAT3 is essential for the signal transduction induced by numerous cytokines (IL-6, IL10, IL-11, IL-17, IL-21 and IL-22), a deficiency thereof will lead to upregulation of many Th1 cytokines and downregulation of pro-inflammatory and antiinflammatory responses regulated by IL- 6 and IL-10, respectively [22]. However, IL-10 and IL-21 induce differentiation of B cells into Ab-secreting cells (69), implying that aberrant STAT3 downstream signaling may be responsible for defective Ag-specific $A b$ responses in AD-HIES patients.

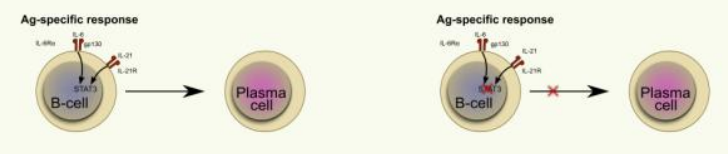

Figure 3: Ag-specific response in normal defence - left and in STAT3 deficiency-right.

Patients with AD-HIES had skeletal abnormalities that are not characteristic for the AR form. Leung et al. (1988) discovered an increased ability of monocytes to resorb bone in HIES patients when compared to healthy individuals [33]. Monocytemediated bone resorption can be stimulated by TNF- $\alpha$ and IL-1 $\beta$ [70]. Evidence from STAT3-deficient murine myeloid cells showed that they produce high quantities of TNF- $\alpha$ and IL-1 $\beta$ [71]. It is likely then that skeletal abnormalities in AD-HIES patients develop because of the increased level of these cytokines [33].

The cause for the highly elevated IgE levels was investigated through the generation of an IL-21R deficient mouse, where the finding of high IgE levels was associated with the role of STAT3 in mediating IL-21 receptor signaling [22, 72].

\section{AR-HIES (DOCK8 mutations)}

DOCK8-deficient patients exhibit multiple abnormalities of the immune system, including high serum $\operatorname{lgE}$, eosinophilia, lymphopenia and antibody abnormalities. As lymphopenia affects both CD4 and CD8 $T$ cells, Zhang et al. examined the $T$ cells responses after in vitro stimulation of the $T$ cell receptor in 11 cases of undefined, combined immunodeficiency or autosomal recessive hyper-lgE syndrome where they established a DOCK8 deficiency [23]. They also investigated functional defects in CD8 T cells, where they found that CD8 T cells from DOCK8-deficient patients fail to activate, divide, and expand. Because of the antiviral role of the $\mathrm{T}$ cells, they measured antiviral cytokines IFN- $\gamma$ and TNF- $\alpha$, which they found to be decreased as well. This can explain the increased susceptibility of DOCK8-deficient AR-HIES patients to viral infections.

A second explanation of lymphopenia in DOCK8-deficient patients may be that DOCK8 plays a role in $\mathrm{T}$ cell migration. The role of DOCK180-related family members in chemotaxis is well known and may help to associate it with the increased susceptibility to cutaneous, but not systemic viral infections in most 


\section{DOCK8-deficient patients.}

In addition to their lymphopenia, DOCK8deficient patients have antibody abnormalities. Besides their elevated serum $\lg \mathrm{E}$, which could be a result of a selection bias, patients have low IgM. In two patients who were immunized with neoantigen bacteriophage, a secondary challenge failed to elicit isotype class switching or memory responses, suggesting possible defects in $\mathrm{T}$ cell induced $\mathrm{B}$ cell functions [23].

In 2009, Al Khatib et al. provided experimental evidence suggesting that the DOCK8 deficiency coincided with defects in Th17 cells, which could be used to explain the susceptibility to Candida infections in AR-HIES patients [73].

\section{AR-HIES (TYK2 mutations)}

Minegishi et al. in 2006 described an ARHIES patient with TYK2 mutations [20]. They examined the immunological defects in this patient and suggested that in the absence of TYK2, IL-12 and type I IFN signaling are abnormal leading to diminished Th1 differentiation and IFN- $\mathrm{Y}$ production. It is most likely that this defect is responsible for the susceptibility to intracellular bacterial infections, which is the main difference between the DOCK8 AR-HIES and TYK2 AR-HIES. The defect in type I IFN signaling results with susceptibility to herpes virus infections [21].

\section{Conclusion}

The attempt to relate HIES-specific genetic and molecular markers with the observed clinical infectious phenotype has proven to be very effective. The combination of a basic scientific and a clinical approach appears to be essential for establishing new knowledge regarding fundamental immunological mechanisms. Patients with HIES require constant surveillance regarding infections and chronic lung disease. With early diagnosis, the distinction of the two forms and treatment of infections, most patients with HIES can lead full lives, and become productive adults.

\section{Acknowledgements}

Ss Cyril and Methodius University of Skopje $\mathrm{PhD}$ School covered publication fee for this review article.

\section{References}

1. McKusick VA. Mendelian inheritance in man. Catalogs of human genes and genetic disorders. 12th ed. Baltimore: Johns Hopkins University Press, 1998.
2. Davis SD, Schaller J, Wedgwood RJ. Job's syndrome: recurrent, "cold," staphylococcal abscesses. Lancet. 1966;1:1013-5.

3. White LR, lannetta A, Kaplan EL, Davis SD, Wedgwood RJ. Leucocytes in Job's syndrome. Lancet. 1969;;1(7595):630.

4. Buckley RH, Wray BB, Belmaker EZ. Extreme hyperimmunoglobulinemia $E$ and undue susceptibility to infection. Pediatrics. 1972;49:59-70.

5. Donabedian $H$, Gallin JI. The hyperimmunoglobulin $E$ recurrent-infection (Job's) syndrome. A review of the $\mathrm{NIH}$ experience and the literature. Medicine (Baltimore). 1983;62(4):195-208.

6. Dreskin SC, Goldsmith PK, Gallin JI. Immunoglobulins in the hyperimmunoglobulin $E$ and recurrent infection (Job's) syndrome. Deficiency of anti-Staphylococcus aureus immunoglobulin A. J Clin Invest. 1985;75(1):26-34.

7. Borges WG, Hensley T, Carey JC, Petrak BA, Hill HR. The face of Job. J Pediatr. 1998;133(2):303-5.

8. Grimbacher B, Holland SM, Gallin JI, Greenberg F, Hill SC, Malech HL, Miller JA, O'Connell AC, Puck JM. Hyper-lgE syndrome with recurrent infections--an autosomal dominant multisystem disorder. N Engl J Med. 1999;340(9):692-702.

9. Hill HR, Quie PG, Pabst HF, Ochs HD, Clark RA, Klebanoff SJ, Wedgwood RJ. Defect in neutrophil granulocyte chemotaxis in Job's syndrome of recurrent 'cold' staphylococcal abscesses. Lancet. 1974;2:617-619.

10. Buckley $\mathrm{RH}$, Becker WG. Abnormalities in the regulation of human IgE synthesis. Immunol Rev. 1978;41:288-314.

11. Del Prete G, Tiri A, Maggi E, De Carli M, Macchia D, Parronchi $P$, Rossi ME, Pietrogrande MC, Ricci M, Romagnani S.Defective in vitro production of gamma-interferon and tumor necrosis factor-alpha by circulating $T$ cells from patients with the hyper-immunoglobulin $\mathrm{E}$ syndrome. $\mathrm{J}$ Clin Invest. 1989;84(6):1830-5.

12. Borges WG, Augustine NH, Hill HR. Defective interleukin12 /interferon-gamma pathway in patients with hyperimmunoglobulinemia $\mathrm{E}$ syndrome. $\mathrm{J}$ Pediatr. 2000;136:176-180.

13. Netea MG, Schneeberger PM, de Vries E, Kullberg BJ, van der Meer JW, Koolen MI. Th1/Th2 cytokine imbalance in a family with hyper-IgE syndrome. Neth J Med. 2002;60:349353.

14. Gudmundsson KO, Sigurjonsson OE, Gudmundsson S, Goldblatt D, Weemaes CM, Haraldsson A. Increased expression of interleukin-13 but not interleukin-4 in CD4+ cells from patients with the hyper-IgE syndrome. Clin Exp Immunol. 2002;128:532-537.

15. Ohga $\mathrm{S}$, et al. Cytokine imbalance in hyper-lgE syndrome: reduced expression of transforming growth factor beta and interferon gamma genes in circulating activated $\mathrm{T}$ cells. $\mathrm{Br} \mathrm{J}$ Haematol. 2003;121:324-331.

16. Ito $\mathrm{R}$, et al. Selective insufficiency of IFNgamma secretion in patients with hyper-IgE syndrome. Allergy. 2003;58:329-336.

17. Wood PM, Fieschi C, Picard C, Ottenhoff TH, Casanova JL, Kumararatne DS.Inherited defects in the interferon-gamma receptor or interleukin-12 signalling pathways are not sufficient to cause allergic disease in children. Eur $\mathrm{J}$ Pediatr. 2005;164(12):741-7.

18. Van Scoy RE, Hill HR, Ritts RE, Quie PG. Familial neutrophil chemotaxis defect, recurrent bacterial infections, mucocutaneous candidiasis, and hyperimmunoglobulinemia $\mathrm{E}$. Ann Intern Med. 1975;82(6):766-71.

19. Renner ED, Puck JM, Holland SM, Schmitt M, Weiss M, Frosch M, Bergmann M, Davis J, Belohradsky BH, Grimbacher 
B. Autosomal recessive hyperimmunoglobulin $E$ syndrome: a distinct disease entity. J Pediatr. 2004;144(1):93-9.

20. Minegishi, Y., Saito, M., Morio, T., Watanabe, K., Agematsu, K., Tsuchiya, S., Takada, H., Hara, T., Kawamura, N., Ariga, T., Kaneko, H., Kondo, N., and 24 others. Human tyrosine kinase 2 deficiency reveals its requisite roles in multiple cytokine signals involved in innate and acquired immunity. Immunity. 25: 745-755, 2006.

21. Minegishi $Y$, Saito M, Tsuchiya S, Tsuge I, Takada H, Hara T, Kawamura N, Ariga T, Pasic S, Stojkovic O, Metin A Karasuyama $H$. Dominant-negative mutations in the DNAbinding domain of STAT3 cause hyper-lgE syndrome. Nature. 2007;448(7157):1058-62.

22. Holland SM, DeLeo FR, Elloumi HZ, Hsu AP, Uzel G, Brodsky $\mathrm{N}$, Freeman AF, Demidowich A, Davis J, Turner ML, Anderson VL, Darnell DN, Welch PA, Kuhns DB, Frucht DM, Malech HL, Gallin JI, Kobayashi SD, Whitney AR, Voyich JM, Musser JM, Woellner C, Schäffer AA, Puck JM, Grimbacher B. STAT3 mutations in the hyper-IgE syndrome. $\mathrm{N}$ Engl $\mathrm{J}$ Med. 2007;357(16):1608-19.

23. Zhang $Q$, Davis JC, Lamborn IT, Freeman AF, Jing H, Favreau AJ, Matthews HF, Davis J, Turner ML, Uzel G, Holland SM, Su HC. Combined immunodeficiency associated with DOCK8 mutations. N Engl J Med. 2009;361(21):2046-55.

24. Alsum Z, Hawwari A, Alsmadi O, Al-Hissi S, Borrero E, AbuStaiteh A, Khalak HG, Wakil S, Eldali AM, Arnaout R, AlGhonaium A, Al-Muhsen S, Al-Dhekri H, Al-Saud B, Al-Mousa $\mathrm{H}$.Clinical, immunological and molecular characterization of DOCK8 and DOCK8-like deficient patients: single center experience of twenty five patients. J Clin Immunol. 2013;33(1):55-67.

25. Chamlin SL, McCalmont TH, Cunningham BB, et al Cutaneous manifestations of hyper-lgE syndrome in infants and children. J Pediatr. 2002; 141:572-575.

26. Eberting CL, Davis J, Puck JM, Holland SM. Dermatitis and the newborn rash of hyper-IgE syndrome. Arch Dermatol. 2004; 140:1119-1125.

27. Grimbacher B, Schaffer AA, Holland SM, Davis J, Gallin JI, Malech HL, Atkinson TP, Belohradksy BH, Buckley RH, Cossu F, Espanol T, Garty BZ, Metamoros N, Myers LA, Nelson RP, Ochs HD, Renner ED, Wellinghausen N, Puck JM. Genetic linkage of hyper-lgE syndrome to chromosome 4. Am J Hum Genet. 1999;65:735-44

28. Buckley $\mathrm{RH}$. The hyper IgE syndrome. Clin Rev Allergy Immunol. 2001; 20:139-154.

29. Freeman A, Kleiner D, Nadiminti $H$, Davis J, Quezado $M$, Anderson V, Puck JM, Holland SM. Causes of death in hyper IgE syndrome. J Allergy Clin Immunol. 2007;119:1234-1240.

30. Freeman AF, Davis J, Anderson VL, Barson W, Darnell DN, Puck JM, Holland SM. Pneumocystis jiroveci infection in patients with hyper-immunoglobulin E syndrome. Pediatrics. 2006;118:e1271-e1275.

31. Hutto JO, Bryan CS, Greene FL, White CJ, Gallin JL. Cryptococcosis of the colon resembling Crohn's disease in a patient with the hyperimmunoglobulinemia $\mathrm{E}$ syndrome. Gastroenterology. 1988;94:808-812.

32. Jacobs DH, Macher AM, Handler R, Bennett JE, Collen MJ Gallin JI. Esophageal cryptococcosis in a patient with the hyperimmunoglobulin E-recurrent infection (Job's) syndrome. Gastroenterology. 1984;87:201-203.

33. Leung DY, Key L, Steinberg JJ, Young MC, Von Deck M Wilkinson R, Geha RS. Increased in vitro bone resorption by monocytes in the hyperาimmunoglobulin $E$ syndrome. J Immunol. 1988;140:84-88.

34. Cohen-Solal M, Prieur AM, Prin L, Denne MA, Launay JM,
Graulet AM, Brazier M, Griscelli C, de Vernejoul MC. Cytokinemediated bone re sorption in patients with the hyperimmunoglobulin E syndrome. Clin Im?munol Immunopathol. 1995; 76:75-81.

35. O'Connell AC, et al. Delayed eruption of permanent teeth in hyperimmunoglobulinemia $\mathrm{E}$ recurrent infection syndrome. Oral Surg Oral Med Oral Pathol Oral Radiol Endod. 2000;89:177-185.

36. Smithwick EM, Finelt M, Pahwa S, Good RA, Naspitz CK Mendes NF Kopersztyck S, Spira TJ, Nahmias AJ. Cranial synostosis in Job's syndrome (Letter). Lancet. 1978; I : 826.

37. Höger $\mathrm{PH}$, Boltshauser E, Hitzig $\mathrm{WH}$. Craniosynostosis in hyper-IgE-syndrome. Eur J Pediatr. 1985;144(4):414-7.

38. Freeman AF, Collura-Burke CJ, Patronas NJ, Ilcus LS, Darnell D, Davis J, Puck JM, Holland SM. Brain abnormalities in patients with hyperimmunoglobulin E syndrome. Pediatrics. 2007;119(5):e1121-5.

39. Lee MW, Choi JH, Sung KJ, Moon KC, Koh JK. Extensive xanthelasma associated with anaplastic large cell lymphoma and hyperimmunoglobulin $\mathrm{E}$ syndrome. Int $\mathrm{J}$ Dermatol. 2003;42:944-946.

40. Crama N, Toolens AM, van der Meer JW, Cruysberg JR. Giant chalazia in the hyperimmunoglobulinemia $\mathrm{E}$ (hyper-lgE) syndrome. Eur J Ophthalmol. 2004;14:258-260.

41. Ling JC, Freeman AF, Gharib AM, Arai AE, Lederman RJ, Rosing DR, Holland SM. Coronary artery aneurysms in patients with hyper IgE recurrent infection syndrome. Clin Immunol. 2007;122(3):255-8.

42. Gorin LJ, Jeha SC, Sullivan MP, Rosenblatt HM, Shearer WT. Burkitt's lymphoma developing in a 7-year-old boy with hyperIgE syndrome. J Allergy Clin Immunol. 1989;83(1):5-10.

43. Leonard GD, Posadas E, Herrmann PC, Anderson VL, Jaffe ES, Holland SM, Wilson WH. Non-Hodgkin's lymphoma in Job's syndrome: a case report and literature review. Leuk Lymphoma. 2004;45(12):2521-5.

44. Oztop I, Demirkan B, Tarhan O, Kayahan H, Yilmaz U, Kargi A, Alakavuklar M.The development of pulmonary adenocarcinoma in a patient with Job's syndrome, a rare immunodeficiency condition. Tumori. 2004;90(1):132-5.

45. Kilic SS, Hacimustafaoglu $M$, Boisson-Dupuis $S$, Kreins $A Y$, Grant AV, Abel L, Casanova JL. A patient with tyrosine kinase 2 deficiency without hyper-IgE syndrome. J Pediatr. 2012;160(6):1055-7.

46. Hill, H. R., Quie, P. G. Raised serum-IgE levels and defective neutrophil chemotaxis in three children with eczema and recurrent bacterial infections. Lancet. 1974; 303: 183-187.

47. Grimbacher B, Holland SM, Puck JM: Hyper-IgE syndromes. Immunol Rev. 2005;203:244-250.

48. Erlewyn-Lajeunesse MD: Hyperimmunoglobulin-E syndrome with recurrent infection: a review current opinion and treatment. Pediatr Allergy Immunol. 2004;11:133-141.

49. Hristomanova S, Grunevska V, Balabanova-Stefanova M, Trajkov D, Petlichkovski A, Kirijas M, Djulejic E, Senev A, Spiroski M. Hyper IgE in a HIV Positive Patient - Case Report. Maced J Med Sci. 2011; 4(1):99-103.

50. Muhammed K: Hyper IgE syndrome: report of two cases with moderate elevation of IgE. Indian J Dermatol Venereol Leprol. 2005;71:112-114.

51. Buckley RH: Disorders of the IgE system. In Immunological Disorders in Infants and Children. Edited by: Stiehm ER. Philadelphia: Saunders, 1996:409-422.

52. Freeman AF, Holland SM: Clinical manifestations, etiology and pathogenesis of the hyper-IgE syndromes. Pediatr Res. 2009; 65:32-37. 
53. Schopfer K, Baerlocher K, Price P, Krech U, Quie PG, Douglas $\mathrm{SD}$. Staphylococcal IgE antibodies, hyperimmunoglobulinemia $\mathrm{E}$ and Staphylococcus aureus infections. N Engl J Med. 1979;300:835-8.

54. Schopfer K, Feldges A, Baerlocher K, Parisot RF, Wilhelm JA Matter L:Systemic lupus erythematosus in Staphylococcus aureus hyperimmunoglobulinaemia $\mathrm{E}$ syndrome. $\mathrm{Br}$ Med $\mathrm{J}$ (Clin Res Ed). 1983;287:524-526.

55. Berger $\mathrm{M}$, Kirkpatrick $\mathrm{CH}$, Goldsmith $\mathrm{PK}$, Gallin Jl: IgE antibodies to Staphylococcus aureus and Candida albicans in patients with the syndrome of hyperimmunoglobulin $\mathrm{E}$ and recurrent infections. J Immunol. 1990; 125:2437-2443.

56. Walsh GA, Richards KL, Douglas SD, Blumenthal MN: Immunoglobulin $\mathrm{E}$ anti-Staphylococcus aureus antibodies in atopic patients. J Clin Microbiol. 1981; 13:1046-1048.

57. Su HC: Dedicator of cytokinesis 8 (DOCK8) deficiency. Curr Opin Allergy Clin Immunol. 2010; 10:515-520.

58. Renner ED, Rylaarsdam S, Anover-Sombke $S$, Rack AL, Reichenbach J, Carey JC, Zhu Q, Jansson AF, Barboza J, Schimke LF, Leppert MF, Getz MM, Seger RA, Hill HR, Belohradsky BH, Torgerson TR, Ochs HD. Novel signal transducer and activator of transcription 3 (STAT3) mutations, reduced $\mathrm{T}(\mathrm{H}) 17$ cell numbers, and variably defective STAT3 phosphorylation in hyper-lgE syndrome. J Allergy Clin Immunol. 2008;122(1):181-7.

59. Blum R, Geller G, Fish LA. Recurrent severe staphylococcal infections, eczematoid rash, extreme elevations of $\mathrm{lgE}$, eosinophilia, and divergent chemotactic responses in two generations. J Pediatr. 1977;90(4):607-9.

60. Leung, D. Y. M., Geha, R. S. Clinical and immunologic aspects of the hyperimmunoglobulin E syndrome. Hemat Oncol Clin North Am. 1988; 2: 81-100.

61. Minegishi $Y$, Karasuyama $H$. Hyperimmunoglobulin $E$ syndrome and tyrosine kinase 2 deficiency. Curr Opin Allergy Clin Immunol. 2007;7(6):506-9.

62. Grimbacher B, Dutra AS, Holland SM, Fischer RE, Pao M, Gallin JI, Puck JM. Analphoid marker chromosome in a patient with hyper-IgE syndrome, autism, and mild mental retardation. Genet Med. 1999;1(5):213-8.

63. Griffiths AJF, Miller JH, Suzuki DT, Lewontin RC, Gelbart WM (1993). "Chapter 5". An Introduction to Genetic Analysis (5th ed.). New York: W.H. Freeman and Company. ISBN 0-71672285-2.
64. Woellner C, Schäffer AA, Puck JM, Renner ED, Knebel C, Holland SM, Plebani A, Grimbacher B. The hyper IgE syndrome and mutations in TYK2. Immunity. 2007;26(5):535; author reply 536 .

65. Milner JD, Brenchley JM, Laurence A, Freeman AF, Hill BJ, Elias KM, Kanno Y, Spalding C, Elloumi HZ, Paulson ML, Davis J, Hsu A, Asher Al, O'Shea J, Holland SM, Paul WE, Douek DC: Impaired TH17 cell differentiation in subjects with autosomal dominant hyper-lgE syndrome. Nature. 2008; 452:773-776.

66. Gaffen SL: An overview of $\mathrm{IL}-17$ function and signaling. Cytokine. 2008;43:402-407.

67. Ochs HD, Oukka M, Torgerson TR: TH17 cells and regulatory $\mathrm{T}$ cells in primary immunodeficiency diseases. J Allergy Clin Immunol. 2009; 123:977-983.

68. Conti HR, Baker O, Freeman AF, Jang WS, Holland SM, Li RA, Edgerton M, Gaffen SL: New mechanism of oral immunity to mucosal candidiasis in hyper-lgE syndrome. Mucosal Immunol. 2011; 4:448-455.

69. Rousset F, Garcia E, Defrance T, Péronne C, Vezzio N, Hsu $\mathrm{DH}$, Kastelein R, Moore KW, Banchereau J. Interleukin 10 is a potent growth and differentiation factor for activated human $\mathrm{B}$ lymphocytes. Proc Natl Acad Sci U S A. 1992;89(5):1890-3.

70. Tanaka, S., K. Nakamura, N. Takahasi, and T. Suda. Role of RANKL in physiological and pathological bone resorption and therapeutics targeting the RANKL-RANK signaling system. Immunol Rev. 2005; 208: 30-49.

71. Takeda K, Clausen BE, Kaisho T, Tsujimura T, Terada N, Förster I, Akira S. Enhanced Th1 activity and development of chronic enterocolitis in mice devoid of Stat3 in macrophages and neutrophils. Immunity. 1999;10(1):39-49.

72. Ozaki K, Spolski R, Feng CG, Qi CF, Cheng J, Sher A, Morse HC 3rd, Liu C, Schwartzberg PL, Leonard WJ. A critical role for IL-21 in regulating immunoglobulin production. Science. 2002;298(5598):1630-4.

73. Al Khatib S, Keles S, Garcia-Lloret M, et al. Defects along the $\mathrm{T}(\mathrm{H}) 17$ differentiation pathway underlie genetically distinct forms of the hyper IgE syndrome. J Allergy Clin Immunol. 2009;124:342-348. 